\title{
Molecular characterization of canine coronaviruses: an enteric and pantropic approach
}

\author{
Mehmet Ozkan Timurkan ${ }^{1}$ (I) $\cdot$ Hakan Aydin ${ }^{1} \cdot$ Ender Dincer $^{2} \cdot$ Nuvit Coskun $^{3}$
}

Received: 22 July 2020 / Accepted: 27 August 2020 / Published online: 1 October 2020

(C) Springer-Verlag GmbH Austria, part of Springer Nature 2020

\begin{abstract}
Canine coronavirus $(\mathrm{CCoV})$ generally causes an infection with high morbidity and low mortality in dogs. In recent years, studies on coronaviruses have gained a momentum due to coronavirus outbreaks. Mutations in coronaviruses can result in deadly diseases in new hosts (such as SARS-CoV-2) or cause changes in organ-tissue affinity, as occurred with feline infectious peritonitis virus, exacerbating their pathogenesis. In recent studies on different types of CCoV, the pantropic strains characterized by hypervirulent and multi-systemic infections are believed to be emerging, in contrast to classical enteric coronavirus infections. In this study, we investigated emerging hypervirulent and multi-systemic CCoV strains using molecular and bioinformatic analysis, and examined differences between enteric and pantropic $\mathrm{CCoV}$ strains at the phylogenetic level. RT-PCR was performed with specific primers to identify the coronavirus M (membrane) and S (spike) genes, and samples were then subjected to DNA sequencing. In phylogenetic analysis, four out of 26 samples were classified as CCoV- 1 . The remaining 22 samples were all classified as CCoV-2a. In the CCoV-2a group, six samples were in branches close to enteric strains, and 16 samples were in the branches close to pantropic strains. Enteric and pantropic strains were compared by molecular genotyping of $\mathrm{CCoV}$ in dogs. Phylogenetic analysis of hypervirulent pantropic strains was carried out at the amino acid and nucleotide sequence levels. $\mathrm{CCoV}$ was found to be divergent from the original strain. This implies that some $\mathrm{CCoV}$ strains have become pantropic strains that cause multisystemic infections, and they should not be ruled out as the cause of severe diarrhea and multisystemic infections.
\end{abstract}

\section{Introduction}

Coronaviruses infect enteric and respiratory system cells in mammals and birds and usually cause mild symptoms. They are enveloped viruses with helical symmetry and a singlestranded RNA genome of positive polarity. They belong to the family Coronaviridae of the order Nidovirales. The subfamily Orthocoronavirinae within the family Coronaviridae consists of four genera: Alphacoronavirus, Betacoronavirus, Gammacoronavirus and Deltacoronavirus. The genus

Handling Editor: Tim Skern.

Mehmet Ozkan Timurkan

motimurkan@atauni.edu.tr

1 Department of Virology, Faculty of Veterinary Medicine, Atatürk University, Yakutiye, Erzurum, Turkey

2 Department of Virology, Faculty of Veterinary Medicine, Dokuz Eylül University, Kiraz, İzmir, Turkey

3 Department of Virology, Faculty of Veterinary Medicine, Kafkas University, Kars, Turkey
Alphacoronavirus includes human coronaviruses (229E and NL63), canine coronavirus (CCoV), feline coronavirus (FCoV), porcine transmissible gastroenteritis virus (TGEV), and porcine respiratory coronavirus (PRCoV) [1].

The coronavirus genome encodes four different structural proteins, $\mathrm{E}$ (envelope protein), $\mathrm{M}$ (membrane protein), $\mathrm{N}$ (nucleocapsid protein), and S (spike protein). In addition, some betacoronaviruses have a membrane-anchored HE (hemagglutinin-esterase) protein. The $\mathrm{S}$ glycoprotein is associated with tropism, binding to cell-surface receptors, fusion, and entry of the virus into cells. Therefore, the $S$ protein is the main target of neutralizing antibodies associated with protective immunity $[2,3]$.

Regarding mutations and genetic evolution observed in coronaviruses, $\mathrm{CCoV}$ strains are divided into two groups, $\mathrm{CCoV}$ types I (CCoV-1) and II (CCoV-2). CCoV-2 also divided into two subtypes: $\mathrm{CCoV}-2 \mathrm{a}$, which is the classical $\mathrm{CCoV}$, and $\mathrm{CCoV}-2 \mathrm{~b}$, which emerged by recombination of CCoV 2a with TGEV $[4,5]$.

The CCoV is generally considered to be the etiological agent of an infection localized in the small intestine 
that can lead to mild gastroenteritis, and such strains are called enteric CCoV. However, a few years ago, a highly virulent, multi-systemic, and fatal strains of $\mathrm{CCoV}$ was isolated from puppies $[6,7]$. CCoV-2a has evolved into two different pathogenic subtypes (enteric/classical and pantropic) based on virulence. A hypervirulent CCoV-2a strain, called pantropic $\mathrm{CCoV}$, was isolated from dead puppies from a pet shop in Italy in 2005. This strain causes serious clinical signs and lesions in different organs, which can be observed postmortem in puppies. In experimental infections in dogs, the disease was found to vary in severity with the age and immune status of animals [8]. Moreover, it has been reported to exacerbate the disease, leading to lymphopenia in the long term [9].

Feline infectious peritonitis (FIP) in cats and MERS/ SARS in humans are significant examples of diseases resulting from molecular evolution and adaptation of coronaviruses to new hosts or cellular receptors. Similarly, a few studies in dogs have suggested that $\mathrm{CCoV}$ is transformed into a pantropic virus as a result of mutations. Although not yet fully understood, studies in France and Belgium [10], Greece [11], Italy [12, 13], China [14], and Brazil [15] have drawn attention to the pantropic $\mathrm{CCoV}$ mutation.

In this study, we investigated hypervirulent pantropic strains of $\mathrm{CCoV}$ that emerged as a result of the evolution of enteric strains, based on $\mathrm{S}$ and $\mathrm{M}$ gene amino acid and nucleotide sequences.

\section{Materials and methods}

\section{Sampling}

A total of 26 dogs with a history of severe diarrhea were used for sampling, two of which died as a result of severe dehydration. Rectal swabs from all 26 dogs and necropsy materials from two dogs that died of severe dehydration were analyzed in this study (Figs. 1-2). All rectal swabs were tested using a rapid test kit for canine coronavirus (Bionote, Korea). All of the samples were stored at $-80{ }^{\circ} \mathrm{C}$ until used. Of the $26 \mathrm{CCoV}$-positive dogs, eight were female and 18 were male. The youngest animal was 1 month old, and the oldest was 10 months; the average age was 4 months. The sampling period of the study was between 2012 and 2014. Of the dogs included in the study, 11 were identified as mixed-breed, and the remaining 15 were of the Kangal, Rottweiler, Labrador, Pincher and Cocker breeds. Detailed information about the dogs is presented in Table 1. All samples were taken from dogs that were brought to Atatürk Animal Hospital of Atatürk University in Turkey for treatment.

\section{Preparation of organ material from dogs}

Only two dogs that died of dehydration were examined postmortem. From these dogs, $0.1 \mathrm{~g}$ of tissue was collected from lung, spleen, liver, and intestine and homogenized with a mortar and pestle, mixed, and placed in a $1.5-\mathrm{ml}$ tubes.

\section{RNA extraction}

Rectal swabs and homogenized tissue samples diluted in $1.5 \mathrm{ml}$ of phosphate-buffered saline (PBS) were centrifuged at $1.500 \times g$ for $10 \mathrm{~min}$ at $4{ }^{\circ} \mathrm{C}$, and the supernatant of each specimen was transferred to a $1.5-\mathrm{ml}$ tube. Nucleic acid isolation was performed using a GF-1 Viral Nucleic Acid Extraction Kit according to the manufacturer's instructions (Vivantis, Malaysia). The extracted RNA suspension was stored at $-80{ }^{\circ} \mathrm{C}$ until used.

\section{Detection and sequence analysis of CCoV}

All samples, including tissue preparations, were subjected to RT-PCR with both S- and M-gene-specific primers. For molecular detection of $\mathrm{CCoV}$, seminested RT-PCR was performed using $\mathrm{CCoV} \mathrm{M}$ gene-specific primers $(\mathrm{CCV}$ 1-2-3) (Table 2) [16]. Then, PCR for the CCoV S gene was performed for genotyping/subtyping purposes. For CCoV1, the primer pair EL1F/EL1R was used, and for CCoV-2, the primer pair S5F/S6R was used (Table 2) [17]. PCR products were analyzed by $1 \%$ agarose gel electrophoresis and sequenced.

\section{Screening for canine enteric pathogens}

All samples included in the study were screened by PCR for canine parvovirus 2 (CPV-2), canine distemper virus, canine adenovirus 1-2, and canine group A rotavirus, using specific primers described previously [18-21]. However, none of the samples were found to be positive for these agents.

\section{Phylogenetic analysis}

For phylogenetic analysis, reference sequences of $\mathrm{M}$ and $\mathrm{S}$ genes of $\mathrm{CCoV}$ were obtained from the GenBank database. To create phylogenetic trees, multiple alignment method of all target sequences was performed using the Clustal $\mathrm{W}$ multiple alignment in the Bioedit 7.2.5 program. 


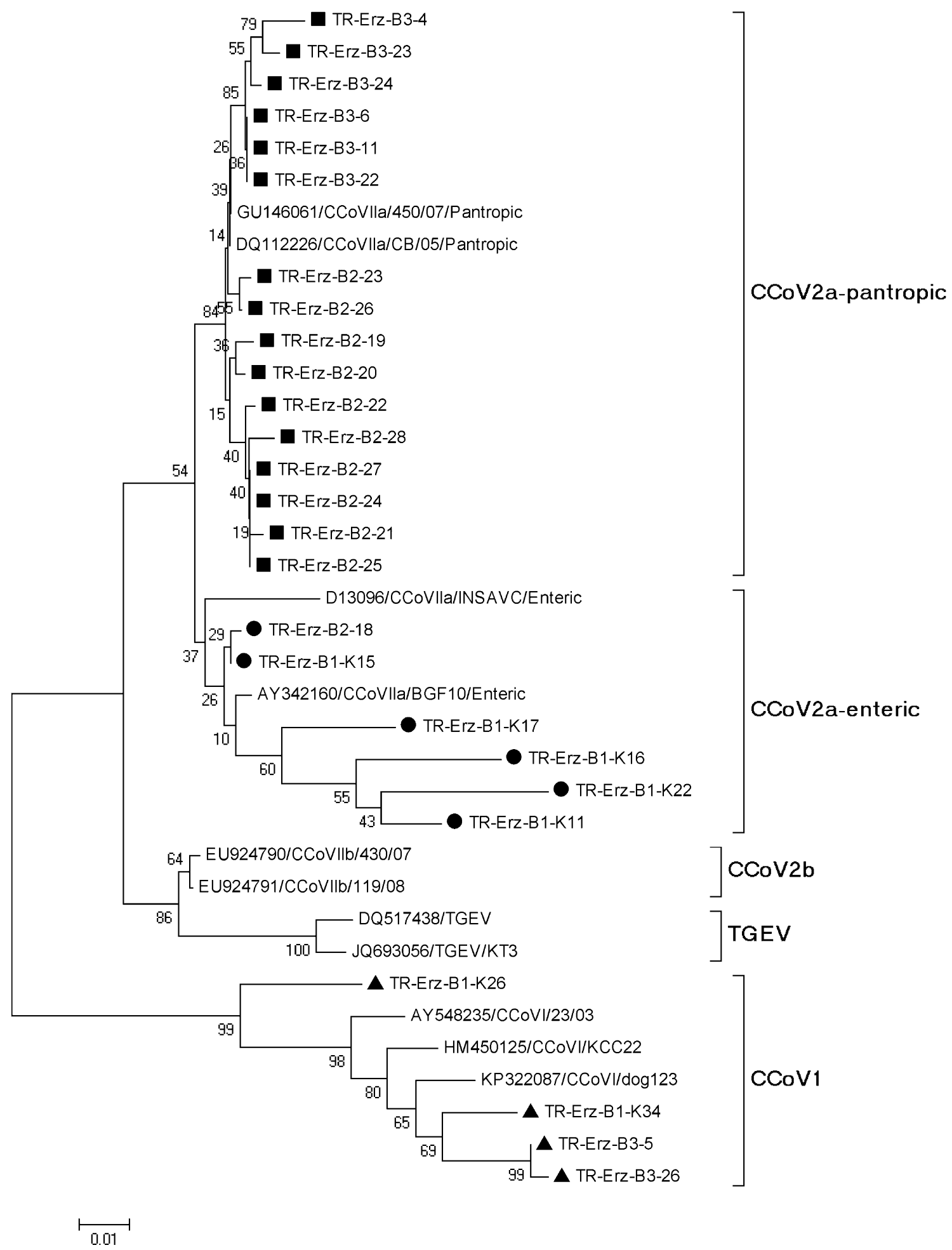

Fig. 1 Phylogenetic tree based on canine coronavirus $M$ gene sequences from Turkey and reference sequences from GenBank. The tree was constructed by the maximum-likelihood algorithm implemented in the MEGA 6 program using p-distance. Values at the nodes (based on 1,000 bootstrap replicates) represent the support for each node and the corresponding clade. The scale bar indicates sub- stitutions per site. Sequences from Turkish pantropic CCoV2a strains are indicated by a square (Ш), Turkish enteric CCoV2a strains are indicated by a black circle (O), Turkish CCoV1 strains are indicated by a triangle $(\boldsymbol{\Lambda})$, and reference sequences are indicated by their accession number 
Fig. 2 Phylogenetic tree based on canine coronavirus $\mathrm{S}$ (spike) gene sequences from Turkey and reference sequences from GenBank. The tree was constructed by the maximumlikelihood algorithm implemented in the MEGA 6 program using p-distance. Values at the nodes (based on 1,000 bootstrap replicates) represent the support for each node and the corresponding clade. The scale bar indicates substitutions per site. Sequences from Turkish pantropic $\mathrm{CCoV} 2 \mathrm{a}$ strains are indicated by a square (口), Turkish enteric CCoV2a strains are indicated by a black circle (๑), Turkish CCoV1 strains are indicated by a triangle $(\boldsymbol{\Delta})$, and reference sequences are indicated by their accession number

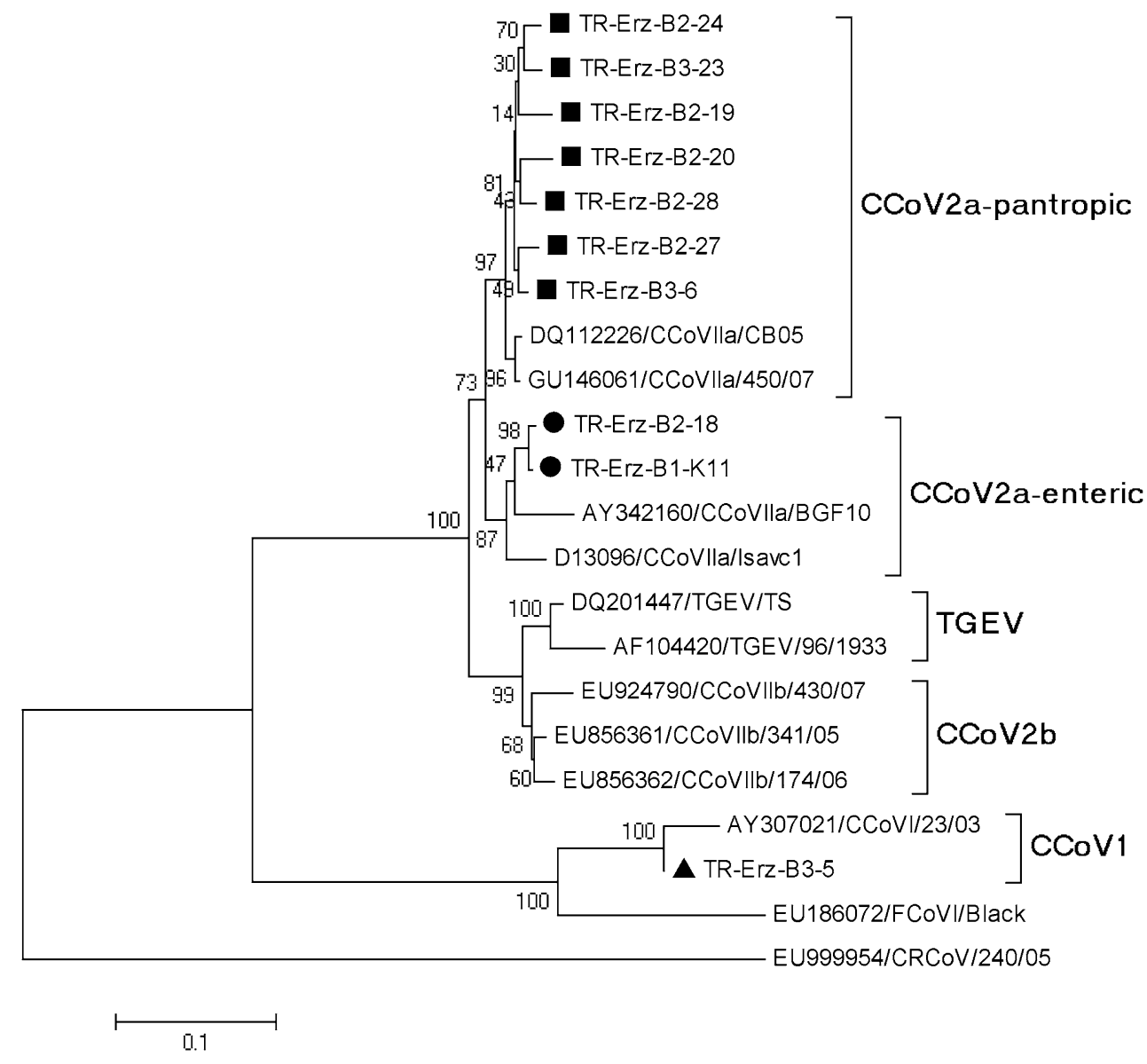

Maximum-likelihood phylogenetic trees were built using the Kimura 2-parameter model with 1000 bootstrap replicates in MEGA 6.0 [22].

\section{Results}

\section{Necropsy findings}

Two dogs presented similar lesions in necropsy. Macroscopically, haemorrhagic enteritis in the small intestines, pneumonia in the lungs, areas of necrosis in the liver, and enlargement of the spleen was observed. Regional mesenteric lymph nodes were enlarged with either petechiae or more extensive haemorrhage. These findings were suggestive of systemic involvement.

\section{Investigation and genotyping of CCoV}

To identify classical enteric and hypervirulent multi-systemic strains of CCoV, $26 \mathrm{CCoV}$-positive dog samples were analyzed by molecular and phylogenetic methods. Amplicons of the expected size were obtained from 10 of the samples for the $\mathrm{S}$ gene and from all 26 samples for the $\mathrm{M}$ gene, using gene-specific RT-PCR. These amplicons were sequenced and used for phylogenetic analysis (Figs. 1 and 2 ), which showed positivity rates for CCoV- 1 and CCoV-2 of $15.38 \%$ (4/26) and $84.62 \%$ (22/26), respectively. All of the CCoV-2 samples were of subtype $2 a$. Subtype $2 b$ was not found. Enteric and pantropic strains were clustered in subtype $2 \mathrm{a}$ within the CCoV-2 genotype. In the CCoV-2a subtype $(n=22)$, six strains $(27.27 \%, 6 / 22)$ were found to be similar to enteric $\mathrm{CCoV}$, while 16 strains $(72.73 \%, 16 / 22)$ were found similar to pantropic $\mathrm{CCoV}$ (Figs. 1 and 2). The genotypes and GenBank accession numbers of these isolates are shown in Table 1.

\section{Nucleotide and amino acid sequence comparisons}

Partial sequences of the $M$ gene of the strains from this study showed nucleotide sequence identity between $85.3 \%$ and $99.4 \%$, and amino acid sequence identity between 91.3\% and $100 \%$. When Turkish CCoV-2a and the previously reported Italian pantropic strain 450/07 (GU146061) were compared, they showed nucleotide sequence identity between $89.3 \%$ and $99.7 \%$ and amino acid sequence identity between $89.8 \%$ and $100 \%$. When UK-INSAVC-1 (D13096) and Turkish enteric CCoV-2a strains were compared, the 
Table 1 Clinical information about the dogs in this study and accession numbers of CCoV strains

\begin{tabular}{|c|c|c|c|c|c|c|c|c|}
\hline Sample ID & CCoV type & Accession no. (M gene) & Accession no. (S gene) & Age (months) & Breed & Sex & Date & Vaccination \\
\hline TR-Erz-B1-K11 & 2a enteric & MT156088 & MT294705 & 3 & Kangal & $\mathrm{F}$ & 2012 & No \\
\hline TR-Erz-B1-K15 & $2 \mathrm{a}$ enteric & MT156089 & - & 3 & Mix & M & 2012 & No \\
\hline TR-Erz-B1-K16 & 2a enteric & MT156086 & - & 4 & Rott & M & 2012 & No \\
\hline TR-Erz-B1-K17 & 2a enteric & MT156085 & - & 3 & Labra & M & 2012 & No \\
\hline TR-Erz-B1-K22 & $2 a$ enteric & MT156087 & - & 5 & Mix & $\mathrm{F}$ & 2012 & No \\
\hline TR-Erz-B1-K26 & 1 & MN913447 & - & 8 & Mix & M & 2012 & No \\
\hline TR-Erz-B1-K34 & 1 & MN913446 & - & 9 & Rott & M & 2013 & No \\
\hline TR-Erz-B2-18 & $2 \mathrm{a}$ enteric & MN913449 & MT294706 & 5 & Kangal & M & 2012 & No \\
\hline TR-Erz-B2-19 & 2a pantropic & MN913429 & MT294700 & 3 & Rott & $\mathrm{F}$ & 2012 & No \\
\hline TR-Erz-B2-20 & 2a pantropic & MN913430 & MT294708 & 4 & Labra & $\mathrm{F}$ & 2013 & No \\
\hline TR-Erz-B2-21 & 2a pantropic & MN913431 & - & 1 & Pinch & M & 2012 & No \\
\hline TR-Erz-B2-22 & 2a pantropic & MN913432 & - & 1 & Kangal & M & 2013 & No \\
\hline TR-Erz-B2-23 & 2a pantropic & MN913433 & - & 2 & Mix & M & 2013 & No \\
\hline TR-Erz-B2-24 & 2a pantropic & MN913434 & MT294701 & 4 & Mix & $\mathrm{F}$ & 2014 & No \\
\hline TR-Erz-B2-25 & 2a pantropic & MN913435 & - & 2 & Mix & M & 2013 & No \\
\hline TR-Erz-B2-26 & 2a pantropic & MN913436 & - & 3 & Pinch & M & 2013 & No \\
\hline TR-Erz-B2-27 & 2a pantropic & MN913437 & MT294702 & 4 & Cocker & M & 2013 & No \\
\hline TR-Erz-B2-28 & 2a pantropic & MN913438 & MT294709 & 1 & Mix & $\mathrm{F}$ & 2014 & No \\
\hline TR-Erz-B3-4 & 2a pantropic & MN913439 & - & 3 & Mix & $\mathrm{F}$ & 2014 & No \\
\hline TR-Erz-B3-5 & 1 & MN913445 & MT294707 & 10 & Mix & M & 2013 & No \\
\hline TR-Erz-B3-6 & 2a pantropic & MN913440 & MT294703 & 5 & Cocker & $\mathrm{F}$ & 2013 & No \\
\hline TR-Erz-B3-11 & 2a pantropic & MN913441 & - & 4 & Kangal & M & 2014 & No \\
\hline TR-Erz-B3-22 & 2a pantropic & MN913442 & - & 4 & Rott & M & 2014 & No \\
\hline TR-Erz-B3-23 & 2a pantropic & MN913443 & MT294704 & 3 & Labra & M & 2012 & No \\
\hline TR-Erz-B3-24 & 2a pantropic & MN913444 & - & 3 & Mix & M & 2013 & No \\
\hline TR-Erz-B3-26 & 1 & MN913448 & - & 9 & Mix & M & 2014 & No \\
\hline
\end{tabular}

Table 2 Oligonucleotide primers used in this study

\begin{tabular}{llllll}
\hline Primer & Gene/type & Sequences $\left(5^{\prime}-3^{\prime}\right)$ & Position & bp & Reference \\
\hline CCV1 & $\mathrm{M}$ & TCCAGATATGTAATGTTCGG & $337-356$ & 409 & Pratelli 1999 \\
CCV2 & & TCTGTTGAGTAATCACCAGCT & $726-746$ & 211 & \\
CCV3 & & GGTGTCACTCTAACATTGCTT & $535-556$ & & \\
EL1F & S/I & CAAGTTGACCGTCTTATTACTGG TAG & $2611-2636$ & 346 & Pratelli 2004 \\
EL1R & & TCATATACGTACCATTATAGCTGAAGA & $2930-2956$ & & \\
S5 & S/II & TGCATTTGTGTCTCAGACTT & $3991-4010$ & 694 & \\
S6 & & CCAAGGCCATTTTACATAAG & $4665-4684$ & & \\
\hline
\end{tabular}

nucleotide sequence identity was between $91.6 \%$ and $97.3 \%$, and the amino acid sequence identity was between $88.3 \%$ and $98.3 \%$. Within the CCoV-1 type group, the nucleotide sequence identity was $95.1-97.9 \%$ and the amino acid sequence identity was 91.6-95\% among Turkish and Italian (AY548235) strains.

The $\mathrm{S}$ gene sequences were $95.9-98.0 \%$ identical at the nucleotide level and 95.0-97.7\% identical at the amino acid level to reference 450/07 (CCoV-2a/pantropic), 95.3-95.4\% at the nucleotide level and 96.3-97.2\% at the amino acid level to reference UK-INSAVC-1 (CCoV-2a/enteric), and
$96.3 \%$ at the nucleotide level and $95.4 \%$ at the amino acid level to reference 23/03 (CCoV-1).

\section{Amino acid analysis}

Various mutations were detected at five different sites in the partial amino acid sequences of the $S$ gene (approximately 222 amino acids). Substitutions were found at position 70 $(\mathrm{D} \rightarrow \mathrm{E}, \mathrm{S}, \mathrm{N}), 127(\mathrm{E} \rightarrow \mathrm{D}, \mathrm{A}), 159(\mathrm{~T} \rightarrow \mathrm{P}), 189(\mathrm{~V} \rightarrow \mathrm{L})$, and $193(\mathrm{~V} \rightarrow \mathrm{I}, \mathrm{T})$. Some of these mutations might be used to distinguish pantropic from enteric strains. 


\section{Discussion}

The importance of emerging (SARS/MERS) and re-emerging (CPV-2c or COVID-19) infections is currently increasing $[2,23,24]$. Therefore, the genetic characteristics of these infectious agents need to be examined frequently due to emerging new types, changes in pathogenesis, and the dynamism of immune escape mechanisms. The emergence of FIP, a coronavirus disease, is an example. Feline enteric coronavirus, which typically caused mild diarrhea due to its affinity for enterocytes in cats, has mutated into the FIP virus, which has adapted to replicating in immune system cells, resulting in a multi-systemic fatal disease (peritonitis, granulomatosis organ damage), creating a completely different clinical manifestation in cats [25]. So far, data on $\mathrm{CCoV}$ infections in puppies have been limited, and the majority of the research has involved serological studies [26]. In the present study, we performed a molecular and bioinformatic evaluation of enteric/pantropic $\mathrm{CCoV}$ strains. There have been many studies worldwide investigating the role of viral agents in the pathogenesis of diarrhea in puppies and adult dogs. In Europe, highly virulent pantropic strains of CCoV-2a, which are fatal in puppies, were reported for the first time by Decaro et al. [8]. An examination of the studies conducted in different countries $[13,15]$ showed that the majority of the studies focused on the $\mathrm{S}$ protein, which is the target of neutralizing antibodies. This is the main approach for identifying pantropic strains; however, in this study, only 10 of the 26 samples yielded an amplicon for this gene region. We therefore also analyzed the $\mathrm{M}$ gene, which is a conserved gene region, to differentiate the pantropic strains. All 26 samples gave a positive PCR result for the M gene. This suggests that the sensitivity of the $\mathrm{S}$ gene PCR might be lower and that using only the $\mathrm{S}$ gene for diagnostics may result in false negatives.

When the analyses are compared, both gene regions gave similar phylogenetic results. In both phylogenetic trees, the pantropic strains clustered together, suggesting that both the $\mathrm{S}$ and $\mathrm{M}$ genes could be appropriate for identifying pantropic $\mathrm{CCoV}$ strains phylogenetically. However, since the PCR sensitivity at the S gene level appears to be lower, this may result in false negatives.

In most studies, enteric agents are generally identified together, i.e., in the form of coinfections. However, in cases where the virulence of the virus is high, virus infections can by themselves cause disease. In our study, no coinfection was detected in any of the 26 positive samples. We believe this is due to the dominant effect of hypervirulent CCoV-2a-pantropic strains. In our study, 16 of the 26 dogs with severe diarrhea symptoms were found to be infected with a pantropic $\mathrm{CCoV}$, as shown by phylogenetic analysis. Especially the detection of pantropic strains from the tissue samples of two dogs (accession nos. MT294700 and MN913434) that died because of dehydration and multi-systemic infection supports the enteric/pantropic hypothesis. Sequence data obtained from rectal swab samples and organ tissue preparations of the two dead dogs were identical. In the individual cases observed here, we did not detect an enteric-to-pantropic change in our sample group. Thus, the dogs in our study are assumed to have been infected with a pantropic strain rather than with an enteric strain that mutated to a pantropic form. Since only two dogs died of enteric disease, it can be concluded that pantropic strains that cause non-lethal symptoms might not get diagnosed and continue to spread within populations.

Nucleotide sequences were compared between GenBank reference strains and the $\mathrm{CCoV}$ strains identified in this study. In previous studies, nucleotide sequence comparisons were only performed for the $\mathrm{S}$ gene but in this study both the $\mathrm{S}$ and $\mathrm{M}$ genes were analyzed, and the results suggest that the $M$ gene also has sufficient selectivity for identifying pantropic $\mathrm{CCoV}$ strains, as well as the $\mathrm{S}$ gene [6]. The pantropic-CCoV S and $\mathrm{M}$ gene sequences identified in our study were similar to those found in other studies at both the nt and aa level. Therefore, we believe that pantropic strains can be distinguished not only by their $\mathrm{S}$ gene sequences but also by their $\mathrm{M}$ gene sequences in future studies.

Pantropic and enteric strains of CCoV-2a have been distinguished in previous studies by phylogenetic analysis based on the S gene [13]. This study shows that the use of the $\mathrm{M}$ gene may be an alternative approach for pathotype identification. Furthermore, when the $\mathrm{S}$ gene of CCoV-2a strains (about 222 amino acids) was examined at the amino acid level, 70 (residues $\mathrm{D} \rightarrow \mathrm{E}, \mathrm{S}, \mathrm{N}), 127(\mathrm{E} \rightarrow \mathrm{D}, \mathrm{A}), 159$ $(\mathrm{T} \rightarrow \mathrm{P}), 189(\mathrm{~V} \rightarrow \mathrm{L})$, and $193(\mathrm{~V} \rightarrow \mathrm{I}, \mathrm{T})$ were found to be different. In particular, amino acids 159 and 189 showed important changes. Amino acid 159 is $\mathrm{T}$ (Thr) in all 2a-pantropic strains, whereas it is $\mathrm{P}$ (Pro) in 2a-enteric strains. Similarly, amino acid 189 is $\mathrm{V}$ (Val) in all 2a-pantropic strains, whereas it is L (Leu) in 2a-enteric strains. At amino acids 70,127 , and 193, there are differences between 2a-pantropic and 2a-enteric strains (Fig. 3). These mutations should allow pantropic strains to be distinguished for enteric strains.

This is the first report of pantropic CCoV in dogs from Turkey. Fecal samples of all dogs with gastroenteritis were positive for $\mathrm{CCoV}$, corroborating the data published previously $[10,13]$. Phylogenetic analysis of the CCoV strains showed that these were similar to those found in other countries. The Turkish samples tended to cluster into a single clade, suggesting a common ancestor for the $\mathrm{M}$ and $\mathrm{S}$ genes. A recent study demonstrated that $\mathrm{CCoV}$-positive puppies exhibit hemorrhagic enteritis like that observed in CPV-2 infections [15]. Thus, $\mathrm{CCoV}$ and other enteric viruses such 

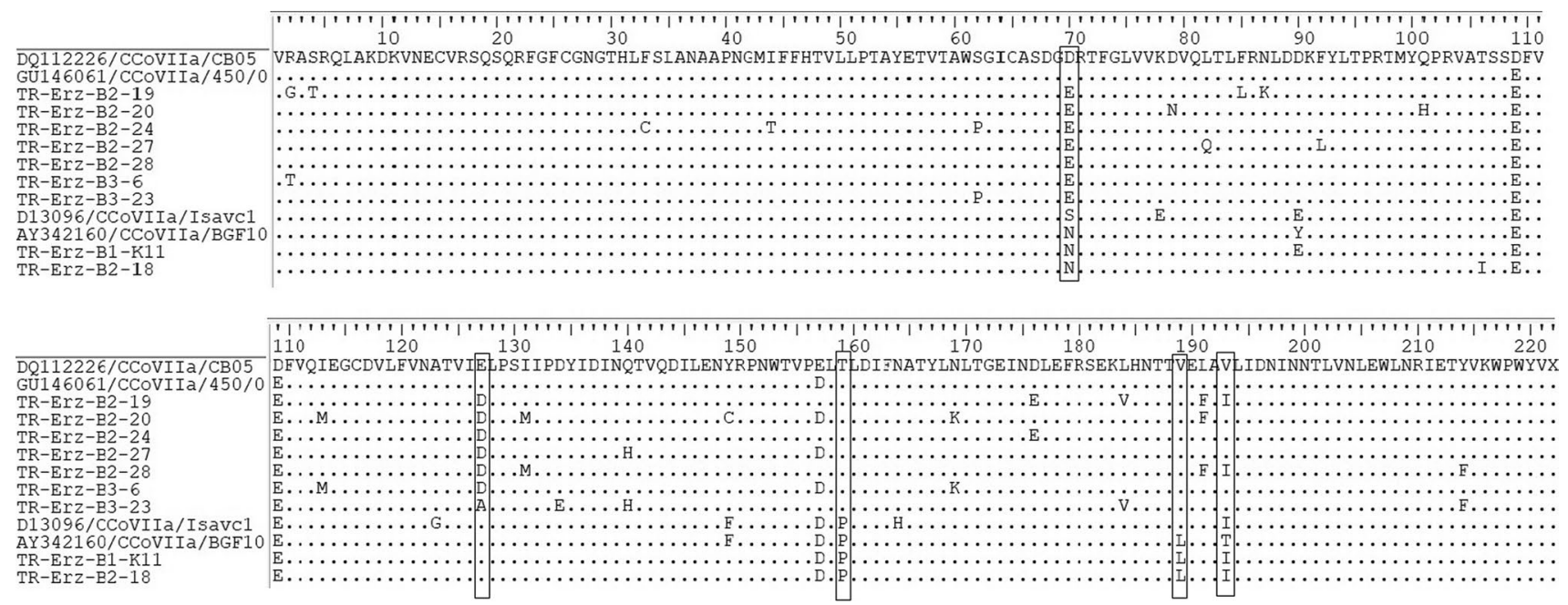

Fig. 3 Analysis of the predicted amino acid sequences of the $\mathrm{S}$ (spike) proteins of enteric and pantropic CCoV strains

as CPV-2 should be kept in mind for differential diagnosis of animals with gastrointestinal symptoms.

In conclusion, pantropic CCoV infection may be a new emerging disease in Turkey and other countries such as France and Belgium. Future epidemiological surveys and molecular studies will help to determine the distribution of pantropic and/or enteric coronaviruses in the dog population in Turkey. Veterinary practitioners and clinicians should be sufficiently informed about the prevalence of pantropic $\mathrm{CCoV}$. Moreover, increased data collection will help to improve the surveillance system in kennels, veterinary clinics, and animal shelters. These data will also help in the design of vaccines, vaccination schedules, drugs, and treatment procedures used for $\mathrm{CCoV}$.

\section{Compliance with ethical standards}

Ethical approval This study was approved by the Ethics Subcommittee of the Atatürk University, Faculty of Veterinary Medicine (date/ protocol number: 16.02.2017/2017-008) in Erzurum, Turkey.

Conflict of interest The authors declare no conflict of interest.

\section{References}

1. Adams MJ, Carstens EB (2012) Ratification vote on taxonomic proposals to the International Committee on Taxonomy of Viruses. Arch Virol 157:1411-1422. https://doi.org/10.1007/ s00705-016-2977-6

2. Yesilbag K, Aytogu G (2020) Coronavirus host divergence and novel coronavirus (Sars-CoV-2) outbreak. Clin Exp Ocul Trauma Infect 2(1):139-147

3. Enjuanes L, Brian D, Cavanagh D et al (2000) Family Coronaviridae. In: van Regenmortel MHV, Fauquet CM, Bishop DHL et al (eds) Virus taxonomy, classification and nomenclature of viruses. Academic Press, New York, pp 835-849

4. Decaro N, Buonavoglia C (2011) Canine coronavirus: not only an enteric pathogen. Vet Clin N Am Small Anim Pract 41:11211132. https://doi.org/10.1016/j.cvsm.2011.07.005

5. Chen S, Liu D, Tian J, Kang H, Guo D, Jiang Q, Liu J, Li Z, Hu X, Qu L (2019) Molecular characterization of HLJ-073, a recombinant canine coronavirus strain from China with an ORF3abc deletion. Arch Virol 164(8):2159-2164. https://doi. org/10.1007/s00705-019-04296-9

6. Buonavoglia C, Decaro N, Martella V, Elia G, Campolo M, Desario C, Castagnaro M, Tempesta M (2006) Canine coronavirus highly pathogenic for dogs. Emerg Infect Dis 12:492-494. https://doi.org/10.3201/eid1203.050839

7. da Costa VG, Saivish MV, Rodrigues RL, de Lima Silva RF, Moreli ML, Krüger RH (2019) Molecular and serological surveys of canine distemper virus: a meta-analysis of crosssectional studies. PLoS One 14(5):e0217594. https://doi. org/10.1371/journal.pone.0217594

8. Decaro N, Elia G, Martella V, Campolo M, Mari V, Desario C, Lucente MS, Lorusso E, Kanellos T, Gibbons RH, Buonavoglia C (2010) Immunity after natural exposure to enteric canine coronavirus does not provide complete protection against infection with the new pantropic CB/05 strain. Vaccine 28:724-729. https ://doi.org/10.1016/j.vaccine.2009.10.077

9. Marinaro M, Mari V, Bellacicco AL, Tarsitano E, Elia G, Losurdo M, Rezza G, Buonavoglia C, Decaro N (2010) Prolonged depletion of circulating CD4 T lymphocytes and acute monocytosis after pantropic canine coronavirus infection in dogs. Virus Res 152:73-78. https://doi.org/10.1016/j.virus res.2010.06.006

10. Zicola A, Jolly S, Mathijs E, Ziant D, Decaro N, Mari V, Thiry E (2012) Fatal outbreaks in dogs associated with pantropic canine coronavirus in France and Belgium. J Small Anim Pract 53:297300. https://doi.org/10.1111/j.1748-5827.2011.01178.x

11. Ntafis V, Xylouri E, Mari V, Papanastassopoulou M, Papaioannou N, Thomas A, Buonavoglia C, Decaro N (2012) Molecular characterization of a canine coronavirus NA/09 strain detected in a dog's organs. Arch Virol 157:171-175. https://doi.org/10.1007/ s00705-011-1141-6

12. Alfano F, Dowgier G, Valentino MP, Galiero G, Tinelli A, Decaro N, Fusco G (2019) Identification of pantropic canine coronavirus 
in a wolf (Canis lupus italicus) in Italy. J Wildl Dis 55:504-508. https://doi.org/10.7589/2018-07-182

13. Decaro N, Mari V, von Reitzenstein M, Lucente MS, Cirone F, Elia G, Martella V, King VL, Di Bello A, Varello K, Zhang S, Caramelli M, Buonavoglia C (2012) A pantropic canine coronavirus genetically related to the prototype isolate $\mathrm{CB} / 05$. Vet Microbiol 159:239-244. https://doi.org/10.1016/j.vetmic.2012.03.039

14. He HJ, Zhang W, Liang J, Lu M, Wang R, Li G, He J, Chen J, Chen J, Xing G, Chen Y (2020) Etiology and genetic evolution of canine coronavirus circulating in five provinces of China, during 2018-2019. Microb Pathog 145:104209. https://doi.org/10.1016/j. micpath.2020.104209

15. Pinto LD, Barros IN, Budaszewski RF, Weber MN, Mata H, Antunes JR, Canal CW (2014) Characterization of pantropic canine coronavirus from Brazil. Vet J 202(3):659-662. https:// doi.org/10.1016/j.tvj1.2014.09.006

16. Pratelli A, Tempesta M, Greco G, Martella V, Buonavoglia C (1999) Development of a nested PCR assay for the detection of canine coronavirus. J Virol Methods 80:11-15. https://doi. org/10.1016/s0166-0934(99)00017-8

17. Pratelli A, Decaro N, Tinelli A, Martella V, Elia G, Tempesta M, Cirone F, Buonavoglia C (2004) Two genotypes of canine coronavirus simultaneously detected in fecal samples of dogs with diarrhea. J Clin Microbiol 42:1797-1799. https://doi.org/10.1128/ jcm.42.4.1797-1799.2004

18. Timurkan M, Oğuzoğlu T (2015) Molecular characterization of canine parvovirus (CPV) infection in dogs in Turkey. Vet Ital 51(1):39-44. https://doi.org/10.12834/vetit.263.908.3

19. Trebbien R, Chriel M, Struve T, Hjulsager CK, Larsen G, Larsen LE (2014) Wildlife reservoirs of canine distemper virus resulted in a major outbreak in Danish farmed mink (Neovison vison). PLoS One 9(1):e85598. https://doi.org/10.1371/journal.pone.0085598

20. Timurkan MO, Aydin H, Alkan F (2018) Detection and molecular characterization of canine adenovirus type $2(\mathrm{CAV}-2)$ in dogs with respiratory tract symptoms in shelters in Turkey. Vet Arhiv 88(4):467-479. https://doi.org/10.24099/vet.arhiv.0052

21. Timurkan MÖ, Alkan F (2020) Identification of rotavirus A strains in small ruminants: first detection of G8P [1] genotypes in sheep in Turkey. Arch Virol 165(2):425-431. https://doi.org/10.1007/ s00705-019-04476-7

22. Tamura K, Stecher G, Peterson D, Filipski A, Kumar S (2013) MEGA6: molecular evolutionary genetics analysis version 6.0. Mol Biol Evol 30:2725-2729. https://doi.org/10.1093/molbev/ mst197

23. Lorusso A, Calistri P, Petrini A, Savini G, Decaro N (2020) Novel coronavirus (SARS-CoV-2) epidemic: a veterinary perspective. Vet Ital 56(1):5-10. https://doi.org/10.12834/VetIt.2173.11599.1

24. Polat PF, Şahan A, Aksoy G, Timurkan MO, Dinçer E (2019) Molecular and restriction fragment length polymorphism analysis of canine parvovirus $2(\mathrm{CPV}-2)$ in dogs in southeast Anatolia, Turkey. Onderstepoort J Vet Res 86(1):e1-e8. https://doi.org/10.4102/ ojvr.v86i1.1734

25. Oğuzoğlu TÇ, Muz D, Timurkan MÖ, Maral N, Gurcan IS (2013) Prevalences of feline coronavirus (FCoV), feline leukaemia virus (FeLV), feline immunodeficiency virus (FIV) and feline parvovirus (FPV) among domestic cats in Ankara, Turkey. Rev Méd Vét 164(11):511-516

26. Yeşilbağ K, Yilmaz Z, Torun S, Pratelli A (2004) Canine coronavirus infection in Turkish dog population. J Vet Med Series B 51(7):353-355. https://doi.org/10.1111/j.1439-0450.2004.00773 . $\mathrm{x}$

Publisher's Note Springer Nature remains neutral with regard to jurisdictional claims in published maps and institutional affiliations. 